\title{
Variations in Characteristics of the Barents Branch of the Atlantic Water in the Nansen Basin under the Influence of Atmospheric Circulation over the Barents Sea
}

\author{
A. Yu. Rozhkova, I. A. Dmitrenko, D. Baukh, and L. A. Timokhov \\ Presented by Academician A.P. Lisitsyn December 7, 2006
}

Received December 13, 2006

\begin{abstract}
DOI: $10.1134 /$ S1028334X08010339
\end{abstract}
The thermohaline structure of the Arctic Basin (AB) of the Arctic Ocean (AO) is determined to a great extent by an intermediate water layer existing under ice at a depth varying from 100 to $700-1000 \mathrm{~m}$. The water layer is formed by warm North Atlantic Water (AW), which enters the AB by two ways: through Fram Strait and the Barents Sea (Fig. 1). The AW arriving to the AB via Fram Strait extends further eastward along the continental slope of the Eurasian Arctic region and forms the Fram Branch (FBAW). The Barents Branch of the AW (BBAW) was formed by the North Atlantic Water entering the Barents Sea between the Spitsbergen Archipelago and the Scandinavian Peninsula. Both branches merge in the northern Kara Sea [1].

The FBAW, which extends from Fram Strait downstream in the subsurface layer, is isolated from the direct interaction with the atmosphere by a layer of fresher $\mathrm{AB}$ water. In contrast, when crossing the Barents Sea on its surface, the BBAW gets cooled, gives away most of its heat to the atmosphere, and becomes more desalinated due to interaction with fresher water of the Norwegian alongshore current and continental runoff [2]. In the northern Kara Sea, colder, fresh, and heavy waters of the BBAW sink down to depths ranging from 400 to $1000 \mathrm{~m}$ below the layer of the relatively warm, saline, and light waters of the FBAW [2, 3]. Another feature distinguishing the BBAW from the FBAW is the relatively high concentration of dissolved oxygen owing to longer contact with the atmosphere

Russian State Hydrometeorological University, St. Petersburg, Russia

International Arctic Research Center, University of Alaska, Fairbanks, USA

Leibnitz Institute of Marine Sciences, University of Kiel, Germany

Arctic and Antarctic Research Institute,

St. Petersburg, Russia during the BBAW transition through the Barents Sea [2-4].

A long-period variation in the temperature and salinity of the AW layer in the $\mathrm{AB}$ is mainly determined by the water exchange with the Atlantic Ocean $[5,6]$. However, the contribution of BBAW and FBAW remains debatable. For instance, recent warming of the AW layer in the 1990s is related to an increased inflow of the BBAW [7]. The state of the AW layer has been monitored systematically along the continental slope of the Eurasian Arctic region since 2002 within the framework of the Russian-American Project "The System of Oceanographic Observations in the Amundsen and Nansen Basins of the Arctic Ocean." In 2004, a dramatic rise in the $\mathrm{FBAW}$ temperature by $0.8^{\circ} \mathrm{C}$ was recorded on the continental slope of the Laptev Sea. This was later attributed to an increased inflow of the AW through Fram Strait in 1999 [6, 8]. Since that time, a steady rise in the temperature of the FBAW core has been recorded in the northeastern Laptev Sea. A simultaneous temperature rise was also recorded in the BBAW. However, it remains unclear whether or not the temperature rise was caused by processes of vertical mixing between the FBAW and BBAW in the course of their transit from their merger region $\left(\sim 70^{\circ} \mathrm{E}\right)$ to the investigation area in the years $2002-2004\left(126^{\circ}-140^{\circ} \mathrm{E}\right)$. In the years 2005-2006, the observation area was expanded in the westward direction (Fig. 1) up to $95^{\circ} \mathrm{E}$ (2005) and $36^{\circ} \mathrm{E}$ (2006). This work is devoted to analysis of changes in the characteristics of the BBAW core in the years 2005-2006 in the immediate vicinity of the BBAW and FBAW merging in the western Laptev Sea in the course of the active rise of the FBAW temperature.

We used for the analysis the data of CTD profiling (vertical profiles of the temperature and salinity) carried out with a SBE19plus probe in September 2005 and 2006 onboard the icebreaker Captain Dranitsyn. The accuracy of the temperature and electroconductivity measurements was $0.005^{\circ} \mathrm{C}$ and $0.0005 \mathrm{~S} / \mathrm{m}$, respec- 


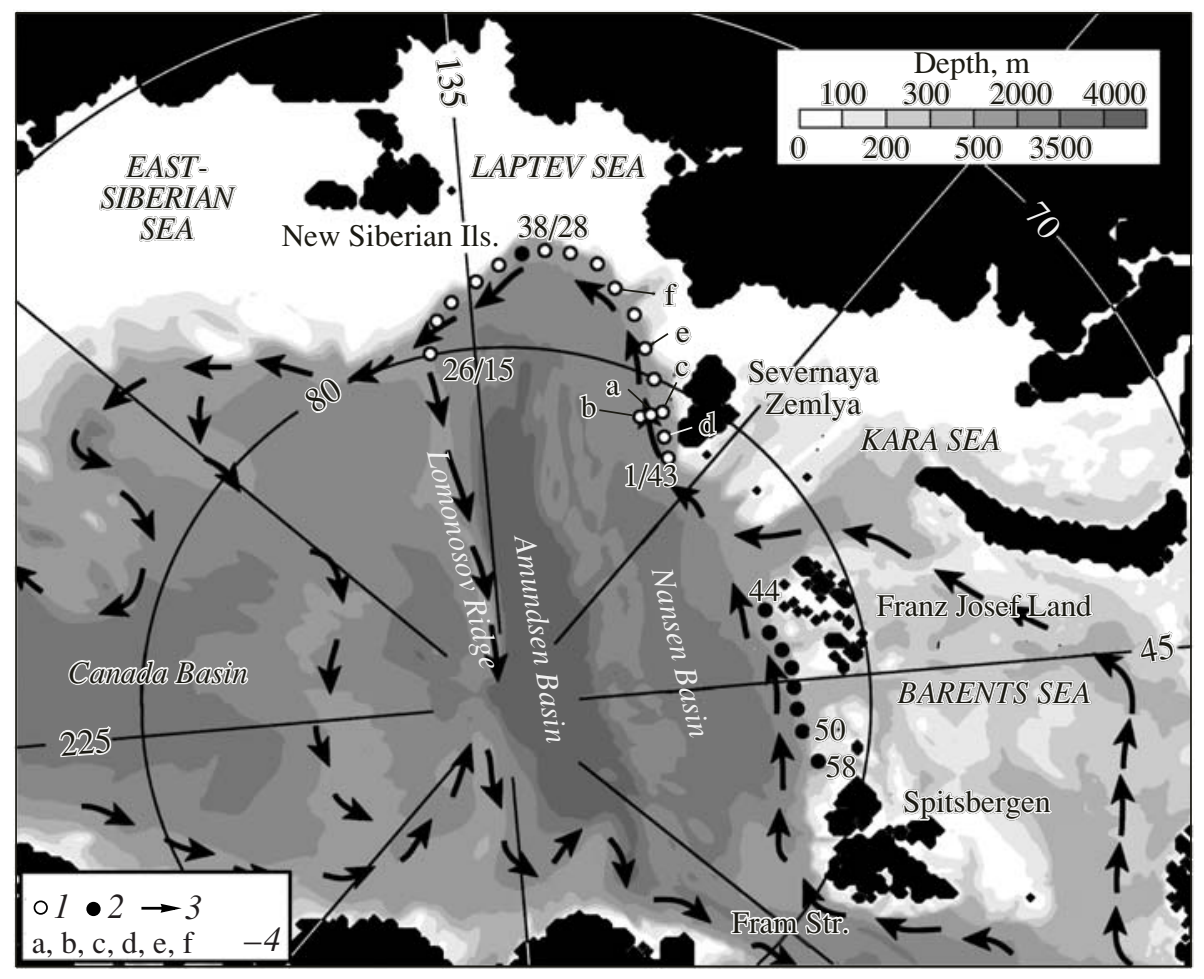

Fig. 1. Location of oceanographic stations along the continental slope of the Arctic Ocean in September (1) 2005 and (1,2) 2006; (3) direction of the Atlantic water flow according to [1]; (4) position of stations used in Figs. 3a-3f.

tively. Water samples for the analysis of the dissolved oxygen content were taken by a rosette of twenty-four 5-1 bathometers. The concentration of dissolved oxygen was determined by titration according to the Winckler method [9] with an accuracy of $0.5 \mathrm{nmol} / \mathrm{kg}$. The vertical distribution of the temperature, salinity, and dissolved oxygen concentration was analyzed in the upper water layer within a depth interval of 5-1100 m (2005) and 5-900 $\mathrm{m}$ (2006). The vertical resolution of CTD data is $\sim 15 \mathrm{~cm}$. Figure $2 \mathrm{~b}$ shows horizons of water sampling for the analysis of dissolved oxygen. Some stations carried out in 2006 (Fig. 2) without water sampling were studied by XCTD detachable thermohaline probes (Lockheed Martin Sippican) with an accuracy of temperature and electroconductivity measurements at $0.02^{\circ} \mathrm{C}$ and $0.003 \mathrm{~S} / \mathrm{m}$, respectively. To study atmospheric processes, we used average monthly records of the atmospheric pressure and wind speed at sea level, which were taken in the database for the reanalysis of atmospheric processes from the Climatic Diagnostic Center in Boulder, Colorado, United States.

The vertical distribution of the temperature, dissolved oxygen, and density in the section along the continental slope for 2005 and 2006 (Fig. 2) reflects characteristic features of the AW and $\mathrm{AB}$ dynamics. In the western part of the section for 2006, from Spitsbergen to Severnaya Zemlya (Northern Land) $\left(31^{\circ}-97^{\circ} \mathrm{E}\right)$, the FBAW temperature gradually decreased from 5 to $2.5^{\circ} \mathrm{C}$ and the concentration of dissolved oxygen was little affected (300-305 nmol/ $\mathrm{kg})$. Two branches of the AB-FBAW and BBAW - are easily identified on the alongshore section in the western Laptev Sea between $97^{\circ}$ and $117^{\circ} \mathrm{E}$ in both 2005 and 2006 . We arbitrarily consider the concentration of dissolved oxygen at $315 \mathrm{nmol} / \mathrm{kg}$ as the boundary of the BBAW layer, and maximal values of dissolved oxygen in the intermediate layer (100-1100 m) allow us to identify exactly the position of the BBAW core in those individual cases when the BBAW is not clearly shown by data on the temperature and salinity (Figs. 3d-3f). Figure 3 shows that the BBAW core located at a depth of 700-850 m is characterized by negative temperatures (from -0.1 to $-0.5^{\circ} \mathrm{C}$ ) as compared to the FBAW, the core temperature of which varies from 1.5 to $2.5^{\circ} \mathrm{C}$; lower salinity (34.82-34.88\%o for the BBAW and 34.85-34.97\%o for the FBAW); and maximal concentrations of dissolved oxygen (315-328 nmol/kg for the BBAW and 303$308 \mathrm{nmol} / \mathrm{kg}$ for the FBAW). Further eastward, it is difficult to identify the FBAW and BBAW with confidence using our data (Fig. 2), probably because of the vertical mixing of the FBAW and BBAW that is also consistent with [3]. A certain spatial nonuniformity in the distribution of the characteristics under consideration $\left(106^{\circ}-\right.$ $112^{\circ} \mathrm{E}$ in 2005 and $119^{\circ}-126^{\circ} \mathrm{E}$ in 2006) can be caused by a shift of the main body of the alongshore AW current relative to the position of stations of the oceanographic section (Fig. 2). 


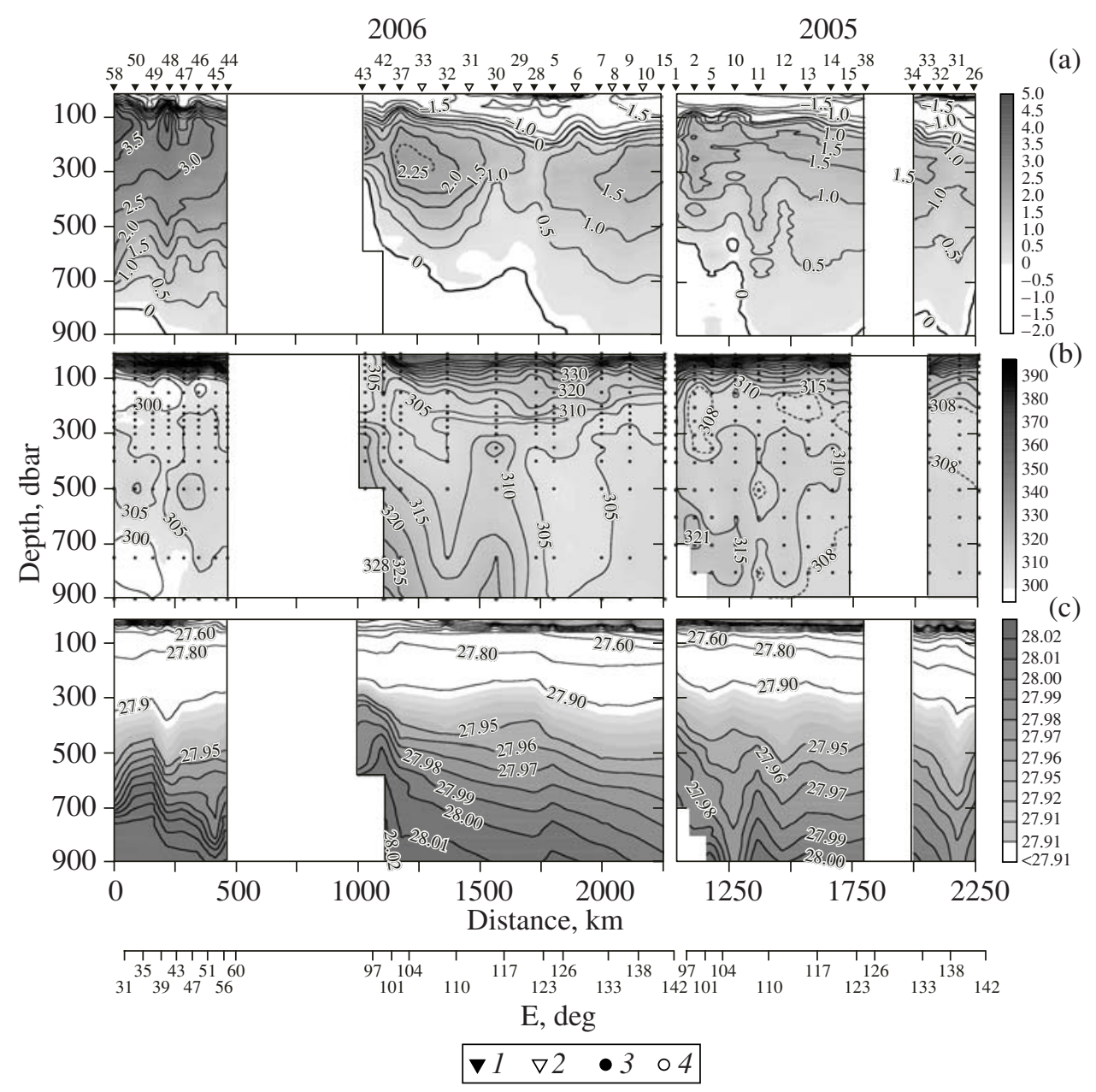

Fig. 2. Vertical distribution of (a) the water temperature $\left({ }^{\circ} \mathrm{C}\right)$, (b) dissolved oxygen $(\mathrm{nmol} / \mathrm{kg})$, and (c) conditional potential density $\left(\mathrm{kg} / \mathrm{m}^{3}\right)$ in the section along the continental slope of the Eurasian shelf in September 2005 and 2006. (1) CTD stations with water sampling; (2) XCTD stations; $(3,4)$ horizons sampled for the concentration of dissolved oxygen. (4) Values of dissolved oxygen concentrations in these horizons are given in Fig. 3.

TS curves (Fig. 3) for stations located in the region downstream of the junction of two AW branches near the Severnaya Zemlya Archipelago (Fig. 1) show a substantial rise in the temperature and salinity in the FBAW from $1.8^{\circ} \mathrm{C}$ and $34.92 \%$, respectively, in 2005 to $2.5^{\circ} \mathrm{C}$ and $34.97 \%$ o, respectively, in 2006 (Figs. 3a$3 \mathrm{c}, 3 \mathrm{e}$ ), which is accompanied by a decrease in the concentration of dissolved oxygen by $3-5 \mathrm{nmol} / \mathrm{kg}$ (Figs. 2, 3). Characteristics of the BBAW core also changed: it became more saline by $0.02-0.05 \%$ and cooler by $0.2-0.4^{\circ} \mathrm{C}$ and the concentration of dissolved oxygen increased, on average, by $7-8 \mathrm{nmol} / \mathrm{kg}$. Hence, in the period 2005-2006, we revealed different tendencies in the transformation of characteristics of two AW branches. Transformations in the FBAW layer are consistent with recent climatic changes in the $\mathrm{AB}[6,8]$, whereas transformations of the BBAW characteristics exceed their limits and require special explanation.

Variation of water exchange between the North Atlantic and the Barents Sea is one of the basic sources for transformation of the BBAW characteristics. However, in all cases, an increase in the AW inflow to the Barents Sea is accompanied by a simultaneous rise of the BBAW temperature and salinity and vice versa. This contradicts the results of our observations. Moreover, the AW inflow to the Barents Sea in the years 2000-2004 demonstrates stable, relatively low values compared to the period 1998-1999 [10].

We assume that the cooling of water and increase in the concentration of dissolved oxygen in the BBAW core in the western Laptev Sea in 2006 were caused by changes in the atmospheric circulation over the Barents and Kara seas in the course of the BBAW transit. The AW flow from the North Atlantic to the Barents Sea and its further eastward expansion is known to be controlled by the atmospheric circulation $[7,10,11]$, which is determined by the state of the Icelandic Low. Its intensification results in enhancement of the southern wind velocity over the Barents and Kara seas, increase of the AW inflow to the western Barents Sea, and the decreas- 
$T,{ }^{\circ} \mathrm{C}$
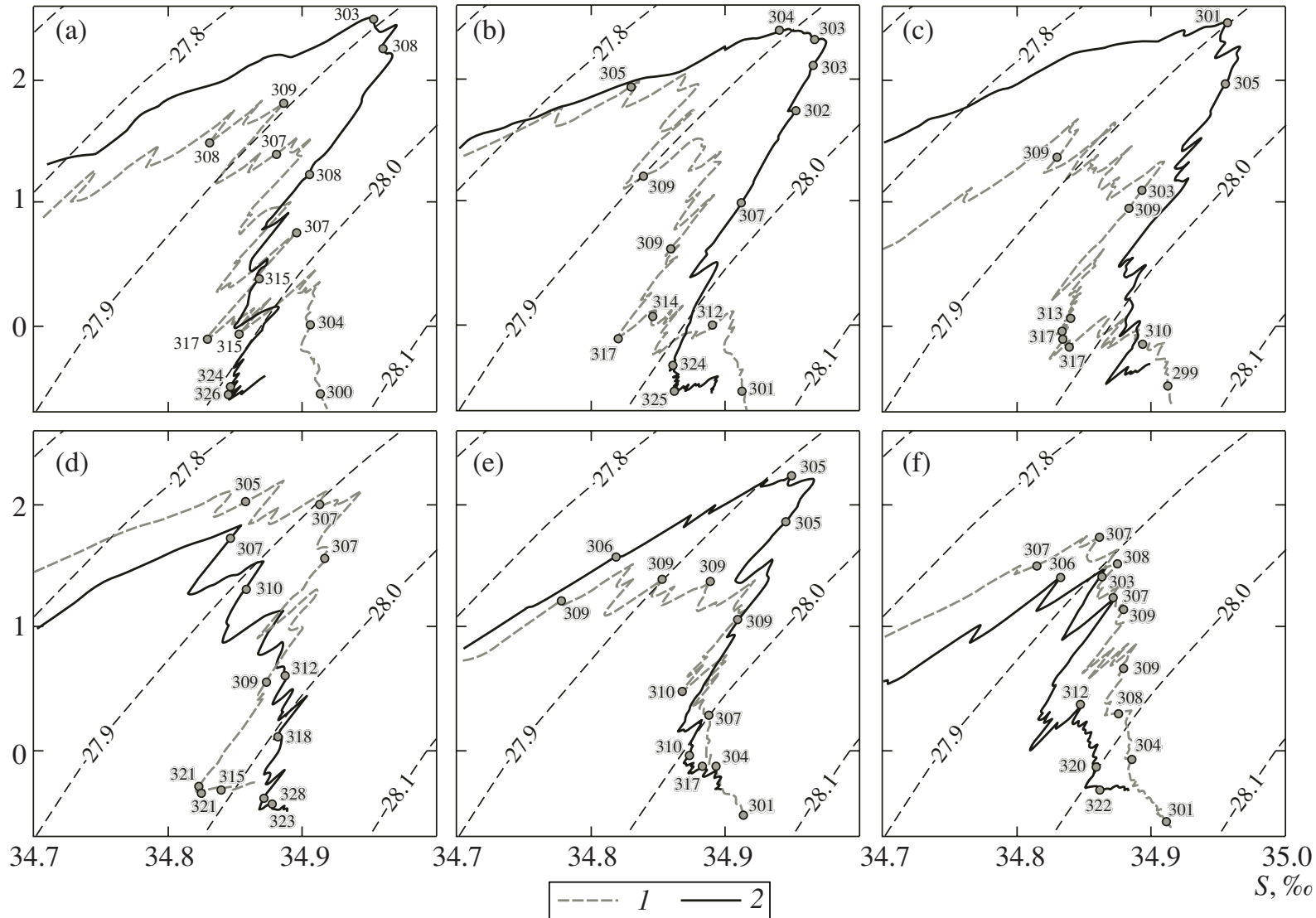

Fig. 3. $T / S$ curves obtained on the basis of CTD profiles in the western Laptev Sea (see Fig. 1) in the same geographical positions in (1) 2005 and (2) 2006. Maximal values of dissolved oxygen concentrations ( $\mathrm{nmol} / \mathrm{kg}$, shown in numerals) determine the position of the BBAW core. Dotted lines show the conditional potential density $\left(\mathrm{kg} / \mathrm{m}^{3}\right.$ ). Stations: (a) 0505, 3706; (b) 0405, 4006; (c) 0305, 4106; (d) 0205, 4206; (e) 1105, 3206; (f) 1305, 3006.

ing transit time of the BBAW prior to its junction with the FBAW in the northern Kara Sea.

Based on the analysis of data on tritium tracers, ${ }^{3} \mathrm{He}$, and chlorine-fluorine-carbon (CFC 11 and 12) for 1993, the period of the BBAW transit from the western Barents Sea to the western Laptev Sea was assessed to be $5 \mathrm{yr}$ [12]. In this connection, the period of the BBAW residence (its characteristics were measured in the western Laptev Sea in 2006) in the surface layer of the Barents and Kara seas may approximately be established as 2001-2005. For measurements carried out in 2005, this period should correspond to 2000-2004. Since the meridional component has a crucial impact on the BBAW transit rate [7], we will further examine its anomalies for the period of 2000-2005 relative to 2000-2004.

For this purpose, we applied a step-by-step summation of monthly values of the meridional component of surface wind averaged for the Barents Sea and the northern Kara Sea (Fig. 4a) and calculated a series of 13 cumulative curves (each with a duration of $4 \mathrm{yr}$ ): the first series was calculated from January 2000, whereas the remaining series were calculated with a successive shift by one month. We recorded a stable positive variation in values of cumulative curves from January and July 2000 (Fig. 2b, values on the horizontal axis are attributed to the series from January 2000) throughout the whole 4-yr period. This variation does not depend on the time shift between the cumulative curves within 1-12 months, which corresponds to possible variations in the BBAW transit time measured in the western Laptev Sea in September 2005 and 2006. This implies the prevalence of southern wind in the period of 2000-2004 compared to 2001-2005. Variation in values of cumulative curves attributed to a time shift of 1-12 months is comparable with values of the meridional wind in the western Barents Sea in the first half of 1999 (Fig. 4a) when a sharp increase in the AW inflow to the Barents Sea was recorded [10].

The results obtained suggest a longer term transit of the BBAW through the Barents and Kara seas, characteristics of which were measured in the western Laptev Sea in 2006 as compared to the BBAW, characteristics of which were recorded in 2005. We believe that more prolonged contact with the atmosphere resulted in BBAW cooling and a higher concentration of dissolved 


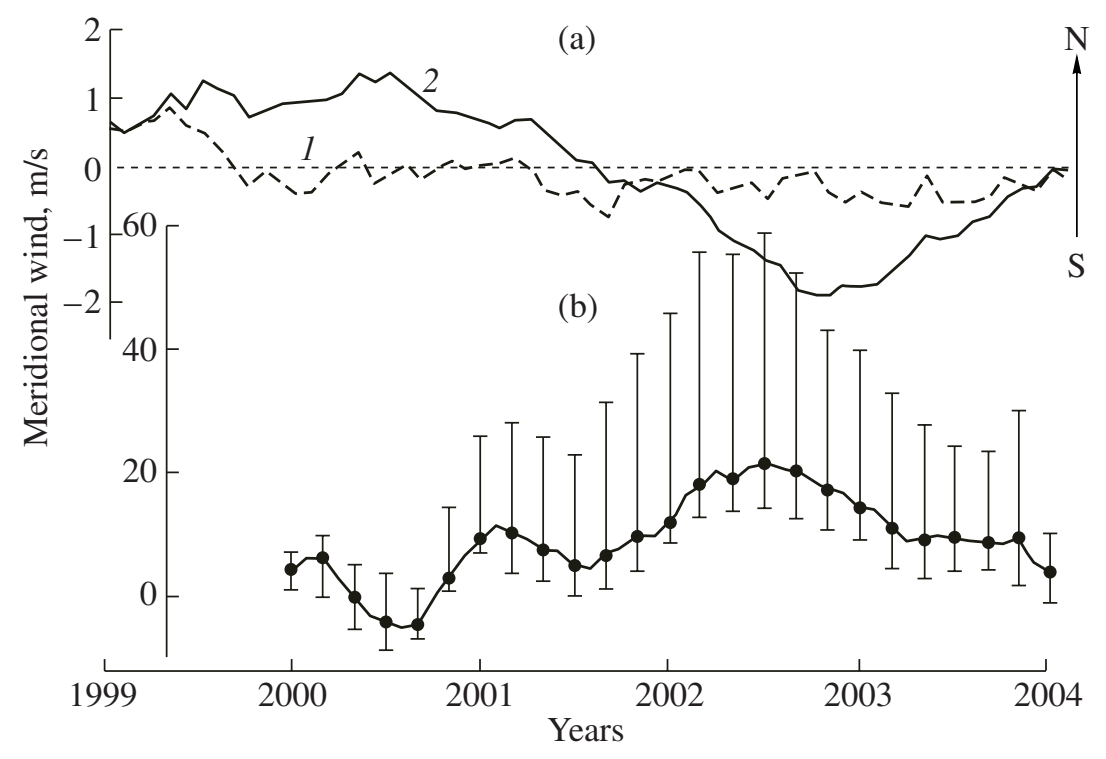

Fig. 4. (a) Meridional component of the surface wind averaged (1) in the western Barents Sea and (2) over the Barents and Kara seas. Monthly mean data are smoothed by the moving average with a 13 -month window. (b) The difference between cumulative values of the meridional component of the surface wind for two time series: from January 2000 and from July 2000. Monthly values averaged for the Barents and Kara seas were used for calculations. Segments show the range of variations in basic values at a shift between series varying from 1 month (lower limit) to 12 months (upper limit).

oxygen. The proposed mechanism does not, however, explain the increase in the BBAW salinity by $0.02-$ $0.05 \%$ o recorded in 2006 compared to 2005 , although values of these salinity variations are comparable with annual variations in the AW salinity by $0.02 \%$ at the entry to the Barents Sea [2].

The higher intensity of ice formation in winter can also be explained by the following alternative mechanism, which also causes the BBAW cooling: an increase in the concentration of dissolved oxygen due to vertical thermohaline convection and an increase in salinity during the brine efflux. However, we believe that the influence of glacial processes on the transformation of the BBAW characteristics is not so essential. Within the period of 2000-2004, only winters of 2000, 2001, and 2002 exhibited negative anomalies equal to one standard deviation in the ice sheet distribution in the Barents Sea [13]. By contrast, positive anomalies of the same amplitude were observed in 2003 and 2004 [13], which should have decreased the intensity of ice formation and brine efflux in the ice-covered sea.

Local processes of intense ice formation in winter polynyas (ice-free waters) beyond the pack ice also can also lead to significant transformation of the BBAW characteristics [2]. Strong southern winds are the basic factors determining the development of polynyas in the Eurasian Arctic region [14]. Since our work has established the prevalence of southern winds in the years 2000-2004 compared to 2001-2005, we cannot consider processes in the polynyas beyond the pack ice in the years 2001-2005 as one of the possible mechanisms responsible for transformations of the BBAW characteristics in 2006.

The basic results of our work are as follows. The cooling and increase in the concentration of dissolved oxygen in the BBAW recorded in 2006 compared to 2005 is attributed to increase in its transit duration before merging with the FBAW in the northern Kara Sea. Variation in the atmospheric circulation over the Barents and Kara seas is the most probable cause. At present, we are carrying out analyses of the oxygen isotope concentration in the BBAW layer. The results of this work will allow us in the near future to assess in greater detail the contribution of processes related to ice formation.

\section{REFERENCES}

1. B. Rudels, P. E. Jones, L. G. Andersen, et al., in The Polar Oceans and Their Role in Shaping the Global Environment. The Nansen Centennial Volume, Geophys. Monogr. Ser. Vol. 85, 1994, pp. 33-46.

2. U. Schauer, H. Loeng, B. Rudels, et al., Deep Sea Res., Part 1 49, 2291 (2002).

3. U. Schauer, B. Rudels, E. P. Jones, et al., Ann. Geophys. 20, 257 (2001).

4. K. K. Falkner, M. Steele, R. Woodgate, et al., Deep Sea Res., Part 1 52, 1138 (2005).

5. I. V. Polyakov, G. V. Alexeev, L. A. Timokhov, et al., J. Climate 17, 4485 (2004).

6. U. Schauer, E. Fahrbach, S. Osterhus, et al., J. Geophys. Res. 109, C06026 (2004). 
7. F. McLaughlin, E. Carmack, R. Macdonald, et al., J. Geophys. Res. 107 (C7), 3082 (2002).

8. I. V. Polyakov, A. Beszczynska, E. C. Carmack, et al., Geophys. Res. Lett. 32, L17605 (2005).

9. J. D. H. Strickland and T. R. Parson, A Practical Handbook of Sea-Water Analysis (J. Fish. Res., Ottawa, 1972), Vol. 167.

10. R. B. Ingvaldsen, L. Asplin, and H. Loeng, J. Geophys. Res. 109, C03021 (2004).
11. M. J. Karcher, R. Gerdes, F. Kauker, et al., J. Geophys. Res. 108 (C2), 3034 (2003).

12. M. Frank, M. S. William, Jr., and R. Bayer, J. Geophys. Res. 103 (C13), 30773 (1998).

13. A. Sorteberg and B. Kvingedal, J. Climate 19, 4772 (2006).

14. P. Winsor and G. Björk, J. Geophys. Res. 105 (C4), 8798 (2000). 